\title{
Condiciones de posibilidad psicosociales de una estudiante de psicología con enfermedad motora de origen cerebral
}

Conditions of Psychosocial Possibilities of a Psychology Student with a Motor Disease of Cerebral Origin

Condições de possibilidade psicossociais de uma estudante de psicologia com doença motora de origem cerebral

\section{Marcela Campos-Sánchez* (iD orcid.org/0000-0002-3533-1497}

\section{Alba Paola Pedraza-Cardozo** iD orcid.org/0000-0001-8193-606x}

\section{(c) $\underset{\mathrm{BY}}{\mathrm{i}}(\mathrm{Sc}$}

* Magíster en Desarrollo Educativo y Social, Corporación Universitaria Minuto de Dios, Bogotá, Colombia. Correo electrónico: marcela.campos@uniminuto.edu

** Magíster en Educación, Neuropsicología y Educación. Profesora Corporación Universitaria Minuto de Dios, Bogotá, Colombia. Correo electrónico: alba.pedraza(a)uniminuto.edu 


\section{Resumen}

La investigación se llevó a cabo en el programa de Psicología de la Corporación Universitaria Minuto de Dios _Uniminuto-, sede principal. Tuvo como objetivo comprender las condiciones de posibilidad psicosociales que estuvieron presentes en el desarrollo del proceso educativo de una estudiante de psicología con enfermedad motora de origen cerebral atetósica. En esta investigación la estudiante cumplió doble rol al ser el sujeto del estudio de caso y asistente de investigación. La metodología de la investigación contempló la reconstrucción autobiográfica de la experiencia educativa en educación superior y la realización de entrevistas a los actores significativos de la experiencia (núcleo familiar, compañeras de estudio, docentes, y administrativos). En el análisis se estableció con Foucault (2007) y Courtine (2006) que las prácticas discursivas que mantienen las relaciones sociales con las personas en condición de discapacidad consisten en la mirada monstruosa, la mirada compasiva y la mirada vacía de subjetividad. Desde la perspectiva foucauldiana del análisis del discurso, se identificaron tres condiciones de posibilidad, como ejercicios de resistencia a dichas prácticas discursivas y, a su vez, claves para desarrollar mejores procesos de educación para la diversidad: (a) disolver la correlación entre parálisis cerebral y discapacidad cognitiva, (b) cuestionar el saber-hacer especializado sobre la discapacidad, y (c) superar el miedo a relacionarse con los cuerpos diversos

\section{Palabras clave}

inclusión; discapacidad física; estudiantes con necesidades especiales; análisis de discurso; desventaja educativa

\section{Keywords}

inclusion; physical disabilities; special needs students; discourse analysis; educationally disadvantaged

\begin{abstract}
The research was carried out as part of the Bachelor of Psychology at Corporación Universitaria Minuto de Dios-Uniminuto, main campus. The purpose was to understand the conditions of psychosocial possibilities present in the development of the educational process of a psychology student with motor disease of athetosic cerebral origin. In this investigation, the student fulfilled a double role as both the subject of the case study and the research assistant. The methodology of the research included the autobiographical reconstruction of the educational experience in higher education and interviewing important actors in the experience (direct family, classmates, teachers, and administrative staff). In the analysis, based on Foucault (2007) and Courtine (2006), it was established that the discursive practices that uphold the social relationships with people with disabilities include looking at them as though they were monsters, giving them a look of compassion or an empty gaze of subjectivity. From Foucault's perspective of discourse analysis, three conditions of possibility were identified, such as exercises of resistance to said discursive practices and, at the same time, keys to develop better education processes for diversity: (a) dissolving the correlation between cerebral palsy and cognitive disability, (b) questioning specialized know-how about disability, and (c) overcome the fear of establishing a relationship with diverse bodies.
\end{abstract}

\section{Resumo}

A pesquisa foi realizada no programa de Psicologia da Corporação Universitária Minuto de Dios -Uniminuto-, campus principal. Esta visou compreender as condições de possibilidade psicossociais presentes no desenvolvimento do processo educativo de uma estudante de psicologia com doença motora de origem cerebral atetósica. Nesta pesquisa, a estudante desempenhou um duplo papel como sujeito do estudo de caso e assistente de pesquisa. A metodologia da pesquisa incluiu a reconstrução autobiográfica da experiência educativa no Ensino Superior e a realização de entrevistas aos atores significativos da experiência (núcleo familiar, colegas, professores e administrativos). Na análise, baseada em Foucault (2007) e Courtine (2006), estabelecemos que as práticas discursivas presentes nas relações sociais com as pessoas com deficiência são: o olhar monstruoso, o olhar compassivo e o olhar vazio de subjetividade. Desde a perspectiva foucaultiana da análise do discurso, identificamos três condições de possibilidade, como exercícios de resistência a essas práticas discursivas e, ao mesmo tempo, dicas para desenvolver melhores processos de educação para a diversidade: (a) dissol108 ver a correlação entre paralisia cerebral e deficiência cognitiva; (b) questionar o saos corpos diversos.

\section{Palavras-chave}

inclusão; deficiência física; estudantes com necessidades especiais; análise de discurso; desvantagem educacional 
Existen algunos trabajos de reflexión de experiencias sobre procesos en la educación superior de estudios en condición de discapacidad. Por ejemplo, algunas instituciones de educación superior (IES) han adelantado programas o discusiones en torno a una educación inclusiva, reconociendo el avance de algunas entidades en este propósito y llevando a cabo un análisis de los avances y de las barreras al respecto (Aldana, 2015; Cárdenas, Parrado y Romero, 2012; Chacón, 2016; Garzón y Molina, 2014; Leguizamón y Molano, 2014; Tamayo y Naranjo, 2013). También, desde el Ministerio de Educación Nacional, en alianza con otras instituciones, han dado cuenta del panorama de la educación superior inclusiva a través de recoger experiencias en diferentes instituciones y de analizar los factores implicados en Ilevarla a cabo (Ministerio de Educación Nacional y Universidad Nacional Abierta y a Distancia, 2014; Ministerio de Educación Nacional y CUN, 2014).

En el rastreo de trabajos de investigación o sistematización de experiencias de educación superior inclusiva, específicamente en relación con personas con parálisis cerebral o enfermedad motora de origen cerebral, se encontraron pocos trabajos que involucraran directamente a los estudiantes en condición de discapacidad, puesto que la mayoría de referentes obedecen a documentos de reflexión y análisis. Dentro de los trabajos que se acercan a conocer y comprender la experiencia de inclusión desde la voz de los estudiantes se encontró el de Salinas, Lissi, Medrano, Zuzulich y Hojas (2013), quienes reportaron un estudio cualitativo basado en la teoría fundamentada, donde analizaron las condiciones que facilitaban y obstaculizan las experiencias en educación superior de estudiantes con discapacidad a partir de la entrevista a 14 estudiantes chilenos en condición de discapacidad (visual, auditiva y motora). Este estudio muestra el interés por acercarse a la experiencia contada por los mismos estudiantes para dar cuenta de la manera en que han construido significado de su proceso académico desde la etapa escolar hasta la universitaria, realizando dos análisis: uno de tipo descriptivo, en torno a las etapas del proceso formativo y la llegada a la universidad, donde se identificaron los factores de tipo personal, social y de contexto; y otro análisis de tipo relacional, en el que se destacaron los factores internos como aspectos del estudiante en cuanto a características personales, de desempeño académico, factores externos o contextuales que fueron facilitadores y obstaculizadores en su experiencia educativa. Dentro de los aspectos que favorecen el proceso se identificaron el apoyo social, en especial el papel de la familia y de los compañeros en condición de discapacidad; los programas de apoyo de las universidades, y el sentido de proactividad y superación de los estudiantes. Como aspectos señalados que dificultaban el proceso se incluyeron las actitudes tanto de docentes como estudiantes, especialmente en la etapa escolar, ya que a nivel universitario mejora un poco; no obstante, se señaló como una

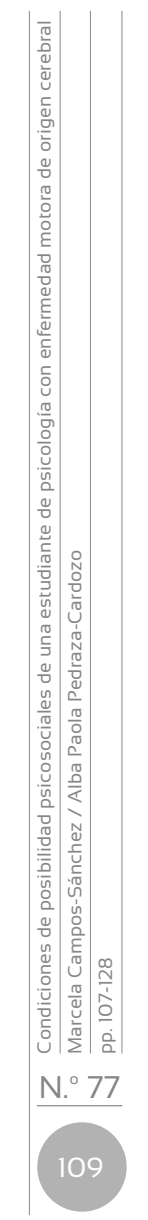


gran barrera la falta de formación del profesorado y la poca adaptación curricular, así como la baja oferta de acceso a la formación universitaria y los pocos recursos de ayuda para el aprendizaje.

En Colombia, Dueñas y Lizarazo (2009) Ilevaron a cabo una investigación en el programa de Biología de la Universidad Pedagógica Nacional con estudiantes sordos para caracterizar cómo se ha abordado el proceso de inclusión con estos estudiantes en el proyecto curricular y de qué manera esto ha contribuido a la construcción de conocimiento profesional. Mediante un estudio de caso, a través de entrevistas y grupo focal, se recopiló la experiencia de docentes, administrativos, estudiantes oyentes y comunidad sorda. Por un lado, se encontró que a nivel pedagógico no se tenía conocimiento sobre la condición de sordera y sus particularidades; por el otro, que frente al campo disciplinar, se requería la creación de señas que reflejaran conceptos de la biología; y, además, que a nivel contextual los diferentes actores de la comunidad educativa desconocían las características de los estudiantes sordos.

Como antecedente en la Corporación Universitaria Minuto de Dios (Uniminuto), Melo (2014) sistematizó la experiencia de acompañamiento del área de Bienestar Universitario a población con discapacidad motora y sensorial, a través de la interpretación de categorías de análisis como acceso, permanencia, bienestar, egreso-vinculación laboral, participación-empoderamiento, y propuso lineamientos para la construcción de una política institucional en dicho centro educativo. En torno a la pregunta sobre los elementos que constituyen la experiencia de Uniminuto con personas con discapacidad visual, auditiva y motora, se presentó una sistematización que se llevó a cabo por fases: planificación (definición de área problemática), reconstrucción histórica (actores activos que viven/ vivieron y relatan la experiencia-contexto institucional), periodización (hechos significativos que permiten sacar secciones en el tiempo) esta última interpretada de manera crítica y teniendo siempre en cuenta la participación de los actores a través de la socialización. A lo largo del documento, se reflejó un interés por dar protagonismo a la reflexión de sentires y significados desde la participación activa de los sujetos. A modo de conclusión, la experiencia de la institución se reconoció como constructiva y afirmativa en relación con una educación inclusiva donde se han incorporado mecanismos de ingreso, flexibilidad en admisión y apoyo a los estudiantes a través de becas, avances en accesibilidad arquitectónica y atención en programas dirigidos específicamente a los estudiantes, acciones de sensibilización a la comunidad educativa y acompañamiento a docentes en aula. No obstante, se reconoce la necesidad de construir una política institucional para las personas en condición de discapacidad y otros grupos poblacionales que permita realmente realizar un proceso 
de inclusión a la diversidad fortaleciendo la permanencia, el egreso y la posterior vinculación laboral. Igualmente, invita a realizar mayores esfuerzos en lo referente a adaptación y flexibilidad curricular, formación docente y en procesos académico-administrativos.

En este horizonte de indagación por la educación superior inclusiva, la presente investigación tuvo como objetivo comprender las condiciones de posibilidad psicosociales que estuvieron presentes en el desarrollo del proceso educativo en educación superior de una estudiante de psicología con enfermedad motora de origen cerebral, tipo atetósica, desde la experiencia directa de la estudiante y de la voz de las personas que ella misma identificó como significativas. En relación con ello, se precisa indicar desde qué postura teórica y metodológica se realiza el estudio.

\section{Psicología cultural y psicología discursiva}

La segunda psicología que inició a finales del siglo xx busca colocar la cultura al mismo nivel de la biología y la economía, moldeando las naturalezas humanas individuales. Esta propuesta denominada psicología cultural se caracteriza, según Cole (1990), por subrayar la acción mediada en un contexto, insiste en la importancia del método genético entendido ampliamente para incluir los niveles histórico, ontogenético y microgenético, fundamentando su análisis en los acontecimientos de la vida diaria, y suponiendo que la mente surge de la actividad mediada conjunta de las personas. Desde esta postura, la mente es, pues, en un sentido importante, co-construida y distribuida. Supone además que los individuos son agentes activos de su propio desarrollo, pero no actúan en entornos enteramente de su propia elección. Finalmente, recurre a metodologías de las humanidades, lo mismo que de las ciencias sociales y biológicas.

Brunner (1990) propone que para no volver a caer en el carácter antihistótico y anticultural como problema fundamental al que se enfrenta la psicología contemporánea, la psicología cultural debe preocuparse por las reglas a las que recurren los seres humanos a la hora de crear significado en contextos culturales, pues "ni siquiera las explicaciones causales más poderosas de la condición humana pueden tener sentido y plausibilidad sin ser interpretadas a la luz del mundo simbólico que constituye la cultura humana" (Brunner, 1990, p. 133).

El mismo autor plantea la narración como una de las principales herramientas de las que se dispone para construir y negociar significados. La psicología narrativa, como también se le conoce, "sostiene un enfoque de un yo narrador/a y narrado; un yo erigido en relator que va tejiendo su discurso sobre la marcha, trazando líneas argumentales, urdiendo tramas, construyendo acontecimientos y creando significados" (Garay, Iñiguez 
y Martínez, 2005, p. 120). Desde un enfoque relacional comprende la autonarración no como una estructura cognitiva privada, sino como un discurso acerca del yo.

El principio básico de la propuesta de la psicología discursiva es la comprensión del lenguaje por su uso. Desde esta perspectiva el discurso es una práctica, y como toda práctica social es posible definir sus condiciones y su contexto de producción:

Los discursos son pues, desde el punto de vista de Michel Foucault, prácticas sociales por lo que a partir de Foucault (1969) se habla más de prácticas discursivas, entendidas como reglas, constituidas en un proceso histórico que van definiendo en una época concreta y en grupos o comunidades específicos y concretos, las condiciones que hacen posible una enunciación. Aunque Foucault no niegue que los discursos estén conformados por signos, rechaza que los discursos tan sólo se sirvan de los signos para mostrar o revelar cosas. Los discursos hacen algo más que utilizar signos, lo que los vuelve irreductibles a la lengua y la palabra (Foucault, 1969). En ese sentido, la tarea en el análisis consiste en tratar los discursos como prácticas que forman sistemáticamente los objetos de que hablan (Foucault, 1966) y abandonar la consideración de los discursos como conjuntos de signos o elementos significantes que son la representación de una realidad. (Garay et al., 2005, p. 109).

Para concluir, Campos (2014) establece que las posibilidades actuales de desarrollo de una psicología cultural posmoderna están en la psicología discursiva, propone que debe asumir los principios de la psicología social socioconstruccionista y su objeto de estudio sería cómo se relaciona la construcción de identidad cultural (de un grupo social) y la construcción de identidades de las instituciones y actores sociales que lo componen. "Dichas identidades tendrían como común denominador al flujo del discurso social y como término operativo de análisis los posicionamientos subjetivos referidos al grupo social y a sus instituciones y actores" (Campos, 2014, p. 54).

\section{El cuerpo-sujeto desde la antinomia "normal" y "anómalo"}

Para Foucault (2007), la norma trae consigo un proyecto normativo en el que todo lo que no se adapte a la norma es desviado, es decir, anormal; argumento que sirve para justificar las lógicas de la exclusión. Los discursos en torno al cuerpo se han hecho por antinomia de lo normal y lo anómalo:

El cuerpo anómalo opera por oposición a un cuerpo ideal y por eso un cuerpo es anómalo cuando abandona el espacio de la norma corpórea, [...] cuestiona el orden establecido, dicho orden, según la época y el espacio, puede estar determinado por la normatividad, el dogmatismo religioso, el poder científico o por los cánones estéticos. (Vignolo, 2008, p. 16). 
Por lo anterior, la relación entre cuerpo e historia es estrecha, el cuerpo adquiere sus significados a través de las adscripciones y proyecciones en contextos sociales y culturales; en otras palabras, la cultura atraviesa y define los cuerpos en nuestras sociedades. Desde la perspectiva antropológica cultural de Courtine (2006), la historia de la deformidad humana es también la de las miradas que se dirigieron hacia ellos en el transcurso del siglo xx. La exhibición de lo anormal en ferias, museos y posteriormente los zoos humanos configuraron una relación con lo que se percibe como diferente; posteriormente, prestaron su rostro para relacionarlo con la peligrosidad, de esta manera la exhibición ayudó a concentrar las angustias colectivas y a extender el poder de la normalización a toda la sociedad:

Una fórmula límpida de Georges Canguilhem elucida esta relación entre el monstruo y la norma: en el siglo xix el loco está en el asilo donde sirve para enseñar la razón y el monstruo está en el frasco del embriólogo donde sirve para enseñar la norma. [...] el salvaje sirve para enseñar la civilización, al mismo tiempo que fundamenta esa jerarquía natural de las razas que exige la expansión colonial. Detrás de las vitrinas de la morgue, el cadáver que recibe a la muchedumbre dominical de curiosos refuerza el miedo al crimen. En la penumbra del museo de cera anatómico las figuras de carnes desbastadas por la heredosífilis inculcan el peligro de la promiscuidad sexual, la práctica de la higiene y las virtudes de la profilaxis. (Courtine, 2006, p. 206).

El proceso histórico de la humanización de los monstruos comienza con el saber teratológico, pues reorganiza el pensamiento de lo monstruoso, el enigma se resuelve con las leyes de la ciencia, y silencia las explicaciones de orden demoniaco, delirios femeninos o incestuosos. De esta manera, la medicina y la biología se hicieron dueñas de las miradas y los discursos sobre los cuerpos deformes y emergen preocupaciones por los efectos teratogénicos del medio ambiente.

"Isidore Geoffroy Saint-Hilaire supo eliminar la confusión entre lo monstruoso y lo anormal, clasificar las anomalías según la gravedad de su naturaleza y reservar la palabra 'monstruosidades' para las desviaciones más graves" (Courtine, 2006, p. 226). Si bien se da un cambio en la sensibilidad y se abre camino a la reeducación, el poder médico afecta jurídicamente el cumplimiento de los derechos civiles al colocar condiciones al engendramiento, considerada como la solución final. Pero serán las consecuencias de la guerra las que provocarán la ruptura más crucial entre monstruo y cuerpo humano, la culpabilidad y las obligaciones morales harán que los miles de mutilados sean vistos como inválidos, desarrollándose una cultura médica y social de la reparación.

Para terminar, resulta útil para la comprensión psicosocial de la mirada sobre los cuerpos deformes la relación que Kappler (1994), citado por Díaz (2012), establece entre la noción de monstruosidad con la de abyección, la

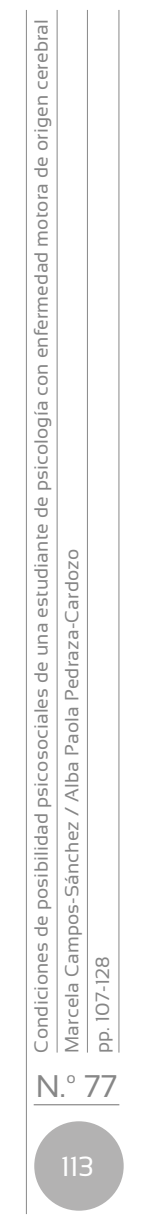


primera, como ya se señaló, aparece ligada históricamente a aquello que se aleja del curso de la naturaleza o va en contra de ella. La mirada de la monstruosidad generada por el proceso de la Conquista de América aporta elementos de análisis para el estudio de los "cuerpos coloniales-cuerpos abyectos" y su relación con los cuerpos nombrados como discapacitados:

La nominación y aparición de cuerpos abyectos (en el sentido con el que son considerados por Judith Butler), y en consecuencia de los cuerpos que -importan, es tanto una estrategia de saber/poder como el acontecimiento concreto de la toma de poder por parte de cuerpos razonables e inteligibles que van a detentar el privilegio de la nominación/dominación de otros cuerpos. [...] Tanto indios como mujeres como discapacitados, en tanto cuerpos oprimidos, relaciones de poder corporizadas pueden considerarse dentro de un proceso múltiple de abyección, por el modo en que la mirada o la visión los espacializa y dispone. Cuerpos abyectos entonces, que como lo plantea Butler (2002: 19): — ... abyección (en latín, ab-jectio) implica literalmente la acción de arrojar fuera, desechar, excluir y, por lo tanto, supone y produce un terreno de acción desde el cual se establece la diferencia. (Díaz, 2012, p. 34).

\section{Metodología}

Para Bonilla y Rodríguez (1997), la principal característica de la investigación cualitativa es su interés por captar la realidad "a través de los ojos" de la gente que está siendo estudiada, es decir, a partir de la percepción que tiene el sujeto de su propio contexto y experiencia; en otras palabras, se devuelve el protagonismo y la voz a los propios sujetos. Desde esta perspectiva de investigación, se escogió el estudio de caso como horizonte metodológico, el cual no parte de una hipótesis o teoría ni pretende generalizar las observaciones; sin embargo, brinda la confianza de alcanzar conocimientos nuevos acerca del caso, hallazgos teóricos novedosos, y claves para la evaluación e intervención en el campo profesional de la educación inclusiva. Para Del Rincón y Latorre (1994), citados por Jiménez y Comet (2016), el estudio de caso debe considerarse como una estrategia encaminada a la toma de decisiones; su verdadero poder radica en su capacidad para generar hipótesis y descubrimientos, en centrar su interés en un individuo, evento o institución, y en su flexibilidad y aplicabilidad a situaciones naturales.

El caso de estudio es el de una mujer de 23 años, estudiante de psicología, diagnosticada con enfermedad motora de origen cerebral (EMOC) atetósica. Es importante aclarar que la participante cumplió un doble rol al ser el sujeto del estudio de caso y asistente de investigación; esta última función fue compartida con la estudiante Stephanía Rincón. La EMOC, de 
acuerdo con Truscelli, Le Matayer y Leroy-Malherbe (2006), es una entidad heterogénea dentro del grupo de parálisis cerebral, donde el componente físico es independiente del componente mental y se considera un trastorno neurológico que genera discapacidad con implicaciones neuromotoras que se expresan en la postura y el movimiento. La EMOC atetósica se caracteriza por movimientos involuntarios de carácter distal de los miembros superiores.

Se encuentran diversas causas en relación con factores prenatales, perinatales y posnatales, con una prevalencia entre 1,5 y 3 por cada mil niños nacidos vivos (Gonzales y Macias, 2008). La ЕмOC se caracteriza por una alteración motora de carácter persistente que conlleva a alteración de los movimientos y dificultad para llevar a cabo movimientos de manera voluntaria; a nivel músculo esquelético se pueden encontrar alteraciones en tono bajo, tono activo aumentado y presencia de reflejos patológicos; pueden presentarse compromiso cognitivo y comorbilidad con alteraciones neurológicas, pero no es la característica principal de la enfermedad (Carreño, 2008). Existe una clasificación de acuerdo con las manifestaciones clínicas de la enfermedad de las partes del cuerpo afectadas (hemiparética, monoparética, dipléjica, cuadrapléjica y triparética), y en relación con las alteraciones del tono muscular y los movimientos involuntarios (espástica, atetósica, distónica, atáxica, hipotónica y mixta).

Teniendo en cuenta la dificultad para comprender el lenguaje verbal del sujeto estudio de caso se optó por realizar la autobiografía mediante la escritura de relatos cortos, reconstruyendo los momentos más significativos de la experiencia educativa, comenzando por las instituciones de rehabilitación, pasando por básica primaria, básica secundaria, hasta la educación superior. Los textos eran leídos por la investigadora en voz alta a la estudiante y se elaboraban preguntas de aclaración o profundización que luego eran respondidas por escrito. Producto de este ejercicio se elaboraron trece microrrelatos.

En una segunda fase se seleccionaron los actores más significativos de la experiencia: familia (padre, madre y hermano), 1 amiga, 3 pares, 3 docentes, y 3 colaboradores administrativos, los cuales fueron entrevistados individual y grupalmente utilizando entrevistas semiestructuradas en las que se abordaron cuatro aspectos: cómo conoce a la estudiante y qué sentimientos e inquietudes le genera, cómo fue el proceso, los momentos más significativos de la relación, y los aprendizajes que esta relación le ha dejado. El cuarto aspecto se desarrolló en torno a las cualidades y retos que tiene la estudiante para el ejercicio de su profesión, de este último aspecto no se profundiza en los resultados en el presente artículo, pues son materia prima de un segundo producto de la investigación elaborado por la estudiante con el fin de compartir desde su experiencia orientaciones psicopedagógicas a estudiantes en condición de discapacidad que se encuentran realizando estudios universitarios. 
Para el análisis del discurso se usó la perspectiva foucaultiana, que se diferencia del análisis de contenido en cuanto:

Es un método que analiza toda producción del lenguaje, particularmente el verbal (sin dejar de lado el audio-visual que posee también discursividad), con el fin de identificar componentes ideológico-políticos, retórico-afectivos, en todo acto de comunicación y de información. Al mismo tiempo relaciona dichos componentes en uno o varios regímenes discursivos, tanto en la continuidad y discontinuidad de la historia. (González-Domínguez y Martell-Gámez, 2013, p. 164).

Iñiguez y Antaki (1994), citados por Garay et al. (2005), plantean que el discurso es un conjunto de prácticas lingüísticas que mantienen y promueven ciertas relaciones sociales, por ende, el análisis del discurso consistió en el estudio de cómo esas prácticas actúan en el presente, manteniendo y promoviendo dichas relaciones sociales. En este sentido, las prácticas discursivas que mantienen las relaciones sociales que se establecen con las personas en condición de discapacidad se definieron a partir de la revisión de los planteamientos de Foucault (2007) y Courtine (2006), estas son la mirada monstruosa, la mirada compasiva y la mirada vacía de subjetividad.

Dichas prácticas discursivas de poder, cumpliendo las veces de categorías de análisis, fueron rastreadas en los discursos producto de la autobiografía y de las entrevistas semiestructuradas realizadas a los actores significativos de la experiencia, ejercicio que permitió develar cómo estuvieron presentes en el desarrollo del proceso educativo. Paralelamente, se identificaron, analizaron y comprendieron las condiciones de posibilidad que se construyeron durante la experiencia en clave de ejercicios de resistencia a las prácticas discursivas de exclusión ya mencionadas.

Teniendo en cuenta las consideraciones éticas de este estudio, a la estudiante con doble rol (participante y asistente de investigación) se le diligenció un consentimiento informado para proteger su identidad, así como detalles de su historia que no hacen parte del estudio; de la misma manera se procedió con los actores significativos a quienes se les realizó la entrevista.

\section{Resultados}

Para Foucault (1996), los discursos construyen los objetos (como la discapacidad) y sus prácticas, por tanto, desde el discurso también es posible analizar las condiciones de posibilidad de dichas prácticas discursivas, es decir "hacia lo que da motivo a la serie aleatoria de esos acontecimientos y que fija los límites" (p. 33). En este sentido, las condiciones de posibilidad identificadas son (a) disolver la correlación entre parálisis cerebral y 
discapacidad cognitiva, (b) cuestionar el saber-hacer especializado sobre la discapacidad, y (c) superar el miedo a relacionarse con los cuerpos diversos. Se pretende que estos hallazgos se traduzcan en claves para avanzar en reales y transformadores procesos de educación para la diversidad.

\section{Disolver la correlación entre parálisis cerebral y discapacidad cognitiva}

La condición de posibilidad más relevante relacionada con la parálisis cerebral es la capacidad cognitiva como práctica discursiva. En el ámbito educativo formal la inteligencia ha sido el factor determinante del ingreso, permanencia, éxito y fracaso de los estudiantes, y establece una jerarquía entre un grupo de personas capacitadas biológica o socioculturalmente para responder a unos dispositivos pedagógicos basados en la capacidad memorística, analítica e interpretativa, a diferencia de otros que, al parecer, no cuentan con las capacidades para responder a dichos dispositivos. En Colombia, la construcción sociocultural en torno a los imaginarios de calidad sigue muy marcada por el concepto de inteligencia, jerarquizando entre los colegios y universidades públicas y privadas. Los imaginarios sociales que atraviesan las instituciones determinan en gran parte los sujetos que allí se forman y sus proyectos de vida. Actualmente en Colombia se está dando un debate importante en este campo con el programa Ser Pilo Paga, algunos de los cuestionamientos planteados incluyen preguntas tales como ¿y qué pasa con los que no son "pilos"?, ¿quién mide qué es ser pilo?, y ¿ cómo hacer para que una sociedad respetuosa de los derechos humanos tenga una educación en donde todos Ileguen a ser "pilos"? Este programa es reflejo de los efectos de las políticas públicas que promueven prácticas segregacionistas (Observatorio de la Universidad Colombiana, 2016).

Ahora bien, esto se agudiza si se ubica la condición de posibilidad de la capacidad cognitiva en las personas con parálisis cerebral, ya que las probabilidades del ingreso, permanencia y éxito se minimizan notablemente. El sistema de educación imperante hace que el conocimiento sea homogéneo para todos, sin importar las particularidades biológicas o culturales, y está diseñado para que en el mismo tiempo todos aprendan de lo mismo. Al no tener clara una política de inclusión para personas en condición de discapacidad, las instituciones aíslan a los sujetos o estos entran a competir por alcanzar unos objetivos pedagógicos bajo criterios estándar, los cuales generan exclusión y altos niveles de frustración.

Para esta investigación, el proceso de acompañamiento de Bienestar Universitario desempeñó un papel importante: la comunicación con el padre-cuidador para establecer las dificultades y posibilidades del caso. Esto contribuyó a la superación del imaginario social de discapacidad cognitiva; el personal psicosocial de Bienestar Universitario recurrió al uso 
del lenguaje biomédico entendiendo que la parálisis cerebral se asocia desde el sentido común con la falta de inteligencia, y ajustaron su diagnóstico a enfermedad motora de origen cerebral (EMOC). Esta nominación pone el acento en el funcionamiento motor y no en el cognitivo. De esta manera, las primeras acciones que se emprendieron fueron a nivel neuropsicológico, orientadas a la medición de la inteligencia, y posteriormente se centraron en comprender el gasto energético que se genera en la ЕмОС atetósica. Esto posibilitó que desde Bienestar Universitario se gestionaran las modificaciones a la infraestructura de la universidad para facilitar los desplazamientos al ingreso e interior de las instalaciones. De esta manera, la transformación de un imaginario social desde las evidencias científicas generó que la inclusión se expresara en la infraestructura física.

En el aula, la práctica discursiva sobre la capacidad cognitiva sufre igualmente una transformación en clave pedagógica para abrir una condición de posibilidad: "Yo pensaba que por sus dificultades motoras, que yo observaba, había dificultades cognitivas en ella, asumía las dificultades cognitivas" (docente B).

Los docentes inicialmente atraviesan por un sin número de cuestionamientos, de temores como son "¿qué hago?, ¿la iré a tener en clase?, ¿cómo le enseño?, ¿cómo será el proceso de enseñarle?, ¿cómo me voy a centrar frente a ella?, ¿cómo mirará?, ¿se le estará movimiento todo el tiempo la imagen?, ¿será que tengo que estar buscándole la mirada?, ¿ cómo voy a tolerar su proximidad sin desesperarme con su movimiento?, ¿hay que ayudarla a ubicarse?, ¿habrá que quitarle todas las mesas?, ¿habrá que ponerle una silla aparte?, ¿ella se podrá sentar sola?, ¿habrá que cargarla?" (docentes A y B).

Estas preguntas son algunas de las reacciones de un sujeto docente frente a los cuerpos diversos en la escuela las cuales se acrecientan producto de la inseguridad que genera no tener experiencia, formación y habilidades para acompañar estudiantes con necesidades educativas diversas. Adicionalmente, buscan resolver la pregunta sobre la capacidad cognitiva sin contar con las herramientas psicométricas especializadas. Sin embargo, la falta de personal especializado para el acompañamiento y la ausencia de tecnología de asistencia para la educación inclusiva se compensa con la capacidad de reflexión-acción de los docentes expresada en, primero, acercarse al estudiante con la certeza de que en él reposan las claves que guiarán el proceso, pues tiene un saber-hacer producto de sus experiencias de enseñanza previas a la educación superior; segundo, recurrir al apoyo de los estudiantes de la clase quienes pueden ayudar a resolver las dudas que el docente tiene; y tercero, ir encontrando un estilo de relación con su estudiante que pasa al nivel de vínculo afectivo atravesado por la confianza y la camaradería: 
[...] me daba miedo enfrentarme a [...] porque yo no sabía cómo hablarle, no sabía cómo entenderla, no sabía si ella me iba a entender, pero en el momento en que yo le digo te voy a tratar igual y ella me responde como me responde, y ella da y ella participa, y ella habla y ella se expresa, yo digo no hay problema. (Docente A).

Como ya se mencionó, la capacidad cognitiva en cuanto condición de posibilidad está mediada por la inteligencia, y esta a su vez es medida por los dispositivos de evaluación. En este aspecto, los ajustes razonables a dichos dispositivos ocupan un lugar significativo dado el compromiso motor de la ЕMOC atetósica. Entre estos ajustes razonables se encuentran los siguientes: no esperar a que la estudiante busque las tutorías, sino buscar a la estudiante y trabajar con ella de manera personalizada para conocer mejor el nivel de sus competencias, presentar los parciales en computador, dar más tiempo para realizar las exposiciones las cuales debió realizar al igual que sus compañeros, y afrontar la ansiedad que le generan, pues está correlacionada con el aumento en los tic y la obstrucción de la verbalización.

Para el caso en estudio, académicamente la estudiante ocupó un lugar de admiración por parte de sus docentes y compañeras por sus habilidades entre las cuales se destaca: capacidad de memoria y capacidad de autorreflexión.

\section{Cuestionar el saber-hacer especializado sobre la discapacidad}

La práctica discursiva del caso que permite dar cuenta de lo diferencial de la experiencia es la manera disruptiva en la que tanto el sujeto como su red de apoyo familiar dan cuenta de la discapacidad. Llama la atención como casi de manera ininterrumpida la familia despliega todos sus recursos personales, profesionales, económicos y emocionales para configurar unos discursos y prácticas sobre la discapacidad que cuestionan los modelos tradicionales. Sin negar la enfermedad y las limitaciones de orden motor y relacional que esta genera, nunca se desiste de un desarrollo integral en donde la dimensión educativa formal es un factor decisivo, y no toleran ni justifican ninguna forma de violencia física o simbólica por su condición.

Para Foucault (1996), "la disciplina es un principio de control de la producción del discurso. Ella le fija sus límites por el juego de una identidad que tiene la forma de una reactualización permanente de las reglas" (p. 22). En este sentido, la red familiar siendo consciente de que las instituciones educativas, su personal y la sociedad en general no están preparados para los procesos de inclusión, dentro de las pautas de crianza fue preparada para responder a las exigencias de un contexto social que excluye, discrimina y no da espera. 
Los diagnósticos iniciales siempre fueron restrictivos en lo referente a dar esperanzas sobre el desarrollo motriz y cognitivo, y a pesar de ello tocaron las puertas de muchos centros educativos, quienes en su mayoría justificaban el no permitir el ingreso por no tener las instalaciones, los equipos y el personal especializado; otros por su parte dieron ingreso por compasión a la situación, pero sin un verdadero compromiso educativo. Estas experiencias hicieron que el sistema familiar desplegara una serie de ejercicios en el marco de la exigencia de derechos para las personas en condición de discapacidad logrando acceder a los servicios educativos y de salud estatales. Los años de rehabilitación en compañía de profesionales en psicología motivan el ingreso a la universidad, proceso que también estuvo marcado por el rechazo de varias instituciones educativas superiores que nunca fueron claros en las razones de la no aceptación. Nuevamente tuvieron que resistirse a los dictámenes de los especialistas en cuanto a las posibilidades de ingresar, mantenerse y concluir una carrera universitaria. Hasta su ingreso a la Uniminuto.

Si bien responder al ritmo imperante fue un recurso de afrontamiento importante que se puso en marcha durante la experiencia universitaria, generó una tensión entre responder a las demandas del contexto desde los criterios externos y la dificultad de comportarse desde sus propios criterios. Es tanta la presión que el sujeto termina por desconocerse a sí mismo, pero, como bien lo dice Foucault (2007), "donde hay poder hay resistencia" (p. 116), y el sujeto se resiste a los ordenamientos que sobre su ser determinan los discursos y prácticas sobre la discapacidad.

Muchas veces los programas de inclusión social, desde mi punto de vista, suelen ser un poco excluyentes, por ejemplo, como cuando una persona ha estado mucho con chuecos ${ }^{1}$ cree que porque se la pasa mucho con chuecos sabe mucho sobre lo que le pasa a los chuecos, entonces se cree con el derecho de aprobar en muchas cosas, por ejemplo si uno va a un parque y ve que están jugando boccia, que es un deporte de chuecos, entonces uno se sienta a mirarlo, lo digo porque a mí me pasa, y viene el entrenador que no es chueco y te dice que por qué no te metes, tú le dices que no que gracias pero no, que solo vas a mirar y entonces te dice "ay pero tú puedes, tu eres capaz, o es que te da pereza?", si me entiendes? Como a querer opinar por uno [...]. Entonces es lo que yo veo en los programas de integración social es que muchas veces quieren hacer de los papás, los cuidadores, entonces no, más bien que nos den las herramientas y nosotros mismos nos demos cuenta si somos o no capaces de, o si cumplimos con las cualidades para hacerlo, o sea que nosotros mismos, de alguna manera, en palabras más, palabras menos, nos estrellemos. (Amiga). 
Para el caso, los ejercicios de resistencia pasan por rechazar cualquier trato "especial" en el ámbito educativo superior. Primero, dejar de asistir a los espacios de acompañamiento de Bienestar Universitario, en donde se encuentran los estudiantes en condición de discapacidad; segundo, no solicitar tutorías personalizadas con los profesores; tercero, no aceptar un proceso de selección diferencial para el ingreso a prácticas profesionales; y, por último, rechazar una oferta de prácticas profesionales en donde la empresa cumplía con las exigencias estatales de inclusión social, pero desde el concepto de la estudiante no le permitían desarrollar competencias profesionales en psicología. Como se mencionó, romper con lo permitido y no permitido por los discursos dominantes de los saberes médicos y psicológicos en torno a la discapacidad genera tensiones con el personal profesionalizado, cuestiona su rol, cuestiona su poder.

La máxima expresión de este proceso de resistencia es tomar la decisión autónoma de cuáles exámenes médicos, tratamientos y medicamentos tomar, pues muchos de ellos son agresivos a nivel motor o emocional. Decisiones que son respetadas por la red familiar, dejando a un lado lo que ellos consideran está bien y lo que está mal para darle lugar al ejercicio de autodeterminación. La experiencia de la práctica profesional le permite mirarse como sujeto y objeto, indagar y cuestionar los procesos de inclusión. La "rehabilitación" la fortaleció, también la excluyó, y finalmente la agotó, y de este análisis surge la pregunta sobre rehabilitarse para qué, para quién. Poner límite a los discursos y prácticas de verdad sobre la discapacidad es un ejercicio de aceptación de su condición y a la vez de exigencia a una sociedad para que la acepte tal cual es, renuncia conscientemente a seguir vinculada a procesos agresivos para parecerse al molde:

[...] siempre he estado encasillada, siempre me han dicho que solo hay dos polos, caminar o no caminar, hablar bien o hablar mal [...] yo no puedo ni debo vivir en estos polos, y no puedo simplemente porque yo no soy ni negro ni blanco, yo soy gris, no quepo en ningún polo radical, porque camino pero no camino bien, hablo pero no hablo bien. (Estudiante-Caso).

En este ejercicio de resistencia ocupa un lugar importante el silencio, el cual no es solo por evitar el gasto energético que le produce físicamente hablar, su silencio es una respuesta consciente al cansancio emocional que le produce tener que explicar quién es a un mundo que no la ve, ni la escucha, fuera de la antinomia normal-anormal.

\section{Superar el miedo a relacionarse con los cuerpos diversos}

Los desplazamientos por el territorio que hacen los cuerpos diversos en la escuela están profundamente regularizados: la misma entrada, la misma ruta y la misma salida, se mantienen constantes en lugar, tiempo y modo. 
Adicionalmente, se convierte en ritual recibir el mismo saludo y el mismo trato "infantilizado" por parte de los colaboradores quienes terminan configurando su red de apoyo para poder movilizarse por la universidad y acceder a los servicios generales de la institución, pero es una relación sin vínculo, es una relación donde el lenguaje no aparece, donde los discursos no se tejen.

Los cuerpos diversos se hacen visibles cuando la aglomeración en el pasillo obstruye el paso y los estudiantes se ven forzados a hacer conciencia de que comparten el espacio con otros. No siempre, y no en todos los casos, hacen este proceso reflexivo, su lenguaje no verbal denota desagrado y no están dispuestos a desacomodarse para abrir espacio, ni en el pasillo ni en el ascensor.

[...] cuando salíamos de clase y con personas que no eran de la carrera de psicología siempre ha habido como esa mirada, pero esa mirada que no se disimula sino como con [indiferencia]: "¿qué le pasa?" Y siempre hemos manifestado que no debería pasar, que nos da malgenio que la miren así, pues si siente curiosidad aunque sea pues disimular, pero la mayoría de las personas la miran con esa intriga y siento a veces con ese morbo de como que la limitan, entonces siempre hemos peleado contra eso y se lo hemos dicho, y ella también a veces hasta contesta. O, por ejemplo, en el Transmilenio que nos ha tocado también las personas no se movilizan, hay que dar un puesto o hay que dar permiso, por el contrario pasan y sí, como que la indiferencia con ella. (Compañera B).

En el salón de clase, los estudiantes pueden pasar todo un semestre sin relacionarse, sin ni siquiera conocer el nombre de sus pares. En relación con los cuerpos diversos buscan un lugar en el salón para mantenerse apartados de ellos, en general, expresan sus opiniones sin tener en cuenta que entre sus compañeros hay personas en condición de discapacidad. Esta pauta de relación cotidiana de evitación configura un patrón de invisibilización del otro, hace más fácil llevar la situación de compartir el mismo espacio con la diversidad.

Hubo varias ocasiones que los profesores se les olvidaba que [...] estaba dentro de la clase y no preparaban un parcial para ella entonces era que nosotros la que acabáramos le ayudábamos a contestar el parcial a ella. En una ocasión una profesora no le pregunto directamente a ella sino me pregunto a mí que como hacían para los parciales y [ella] pues que estaba delante de mí y alcanzo a escuchar se puso muy brava porque le dijo que: ¿por qué no le preguntaba a ella? Que ella era... pues quien más que ella para decirle cómo era que ella podía responder los parciales y pues la profesora se impactó porque no pensó que fuera a tener esa reacción. (Compañera B). 
Esta experiencia da cuenta de cómo se tiene que lidiar con la molestia que genera relacionarse con la diversidad, la cual, en algunos docentes, se expresa en olvido o rechazo. Una de las experiencias más desfavorables narradas tanto por la estudiante como por sus pares fue precisamente durante una exposición en la cual la profesora al no comprenderle empezó a repetir en voz alta lo expuesto, haciendo que la ansiedad de la estudiante aumentara y no pudiera terminar la exposición. Su discurso no puede circular como el de los demás. Esta experiencia da cuenta del orden del discurso del que habla Foucault (1996):

Nadie entrará en el orden del discurso si no satisface ciertas exigencias o si no está, de entrada, calificado para hacerlo. Más preciso: todas las regiones del discurso no están igualmente abiertas y penetrables; algunas están altamente defendidas (diferenciadas y diferenciantes) mientras que otras aparecen casi abiertas a todos los vientos y se ponen sin restricción previa a disposición de cualquier sujeto que hable. (pp. 22-23).

A diferencia de quienes evitan relacionarse, hay también quienes buscan romper el distanciamiento, acomodan la silla para que se siente a su lado y buscan entablar una conversación. Al igual que a los docentes, son muchas las dudas que invaden a los estudiantes antes de construir una relación: "[...] ¿de pronto se va a poner de malgenio, o de pronto se siente mal porque uno la cuestione mucho?, ¿será agresiva?" (Compañeras). Una vez superados los miedos, al entablar un diálogo les queda claro que la molestia se ubica en la pregunta ¿qué puede hacer?, pues su respuesta es que hace todo, solo que lo hace diferente, y espera que se le indague cómo lo hace, pues deja claro que en general puede ocuparse de sus cosas con un alto grado de independencia.

Para la totalidad de los actores sociales entrevistados, el caso es un modelo de superación y, en especial para sus pares, se convierte en un referente que los hace autocuestionarse sobre los límites que se autoimponen para no cumplir con su proyecto de vida académico.

\section{Conclusiones}

Cada cuerpo tiene su armonía y su desarmonía, en algunos casos

la suma de armonías puede ser casi empalagosa, en otros el conjunto de desarmonías produce algo mejor que la belleza.

Mario Benedetti, 2009

Trabajar desde el análisis del discurso de Foucault implica una mirada crítica, una manera disruptiva de comprender lo social que propone una transformación del saber producido. Por ello, nombrar "los cuerpos 
diversos" es un ejercicio de resistencia política desde el lenguaje que tiene como propósito cambiar la mirada sobre el cuerpo, no hay un solo cuerpo, hay muchos, es una respuesta a la exigencia de la igualdad de los cuerpos en una sociedad democrática. Es una propuesta desde las ciencias sociales frente a las consecuencias de las premisas científicas biomédicas que hacen del cuerpo-objeto que prescinde del sujeto/agente social (Campos M., 2017), y finalmente, también constituye un aporte a la difícil separación del cuerpo anormal de la mirada de la monstruosidad. Los cuerpos diversos son mirados y ubicados siempre en categorías patologizantes y provocan la pregunta sobre qué tendrá. Una vez se tiene una respuesta, así no sea científica, la intranquilidad e incertidumbre que genera un cuerpo diverso disminuye. El diagnóstico, sea científico o no, sirve como instrumento biopolítico de patologización. El diagnóstico de la "discapacidad" ubica los cuerpos no solo en un sistema clasificatorio de enfermedades, sino también dentro de un sistema de estratificación sociocultural que los clasifica como anormales y a veces hasta monstruosos.

Desde la perspectiva antropológica cultural de Courtine (2006), en sus estudios sobre los cuerpos anormales la monstruosidad depende de la mirada que se dirige a ella y no está tanto enraizada en el cuerpo del otro como oculto en la mirada del observador. En otras palabras, lo anormal es cuestión de percepción. Separa del cuerpo, la anomalía adquiere un valor psicológico social,

[...] desomatizada, la deformidad se vuelve entonces un problema de comunicación, una patología social de la interacción, con sus inevitables consecuencias: malestar, evitamiento, incomodidad, negación del otro, desintegración de las acciones cara a cara ordinarias, es decir, degradación —incluso negación — del derecho de cada cual al intercambio y a la inclusión social. (Courtine, 2006, p. 253).

Skliar (2002), citado por Heredia (2012), dirá: si hay corporalidad necesariamente hay subjetividad, por más extraña, ajena o extranjera que esa corporalidad se nos presente. La discapacidad tiende a frenar la inmediata adjudicación de una subjetividad activa de la persona en situación de discapacidad.

En muchas de nuestras prácticas cotidianas la situación de discapacidad pone en duda el hecho de poseer una subjetividad activa, hasta que no se demuestre lo contrario. Y aquí llegamos a un punto interesante. Si un determinado cuerpo o subjetividad se nos presenta tan extraño a nuestros parámetros de cuerpos y subjetividades habituales o normales, se tiende a pensar que ese cuerpo o esa subjetividad no tienen voz. Y, cuando la tiene, solo es relevante en tanto y en cuanto exprese lo mismo que se cree — desde diferentes enfoques médico-educativos y sociales en general- debería expresar en esas condiciones. Mecanismos como 
este tienden a negar a la persona que intenta expresarse y ser escuchado desde un afuera — la discapacidad en este caso- que socialmente le ha sido impuesto. (Heredia, 2012, pp. 107-108).

En suma, la historia de la deformidad humana sufrió una transformación; allí donde sobre la mirada del cuerpo no se veía más que monstruosidad empezó a percibirse una discapacidad, mirada que trae otras consecuencias sobre el sujeto; de los pacientes se esperan actitudes de paciencia y posiciones de pasividad (mental y corporal). Por lo anterior, otra condición de posibilidad fue agenciada durante de la investigación vinculando a la estudiante sujeto estudio de caso como asistente de investigación; fue el actor activo no pasivo del proceso, desde la formulación de la pregunta hasta la socialización de los resultados parciales de la investigación. La mayoría de las investigaciones sobre condiciones de posibilidad y de desarrollo en inclusión educativa ponen al sujeto en un lugar de receptor pasivo. Para Planella (2016), a parte de las relaciones de la metáfora del cuerpo como elemento discursivo, es necesario situar las historias narradas por personas que tienen alguna relación "especial" con su cuerpo. El silencio de la cultura y de la sociedad lleva a algunas personas a usar el cuerpo como base de su discurso, se resisten intentando escapar a dicha posición/categoría de "paciente" y se convierten en sujetos activos de su enfermedad y del cuidado de la misma. Son productores de saberes profanos sobre sus cuerpos y sobre la vivencia de la enfermedad.

Para concluir, estas tres condiciones de posibilidad permitieron el desarrollo del proceso académico de la estudiante, por tanto, se configuran en tres claves para generar procesos de educación para la diversidad: (a) la parálisis cerebral no implica en todos los casos compromiso de las capacidades cognitivas, si bien hay un compromiso importante motriz y verbal, el sujeto es capaz de asumir retos académicos y es independiente en la mayoría de actividades; (b) el saber-hacer especializado sobre la discapacidad ordena qué debe y qué no debe hacer el sujeto, de qué es capaz y de qué no, es necesario desobedecer a dichos mandatos pues muchas veces terminan autoimponiendo límites que con un buen acompañamiento son posibles de superar; $y$ (c) relacionarse con la diversidad abre un camino de autodescubrimiento que de ninguna otra manera sería posible: hacer consciente la mirada indiferente o inquieta frente al enigma anatómico puede ser el inicio del camino para superar nuestros propios miedos. 


\section{Referencias}

Aldana, C. (2015). Aproximación a mecanismos de acción que hagan posible la operación de un programa de inclusión de la población con discapacidad de la Pontificia Universidad Javeriana sede Bogotá (tesis de maestría). Pontificia Universidad Javeriana, Bogotá.

Bonilla, E., y Rodríguez, P. (1997). Más allá del dilema de los métodos. La investigación en ciencias sociales. Bogotá: Grupo Editorial Norma-Ediciones Uniandes.

Brunner, J. (1990). Actos del significado. Más allá de la revolución cognitiva. Madrid: Alianza.

Campos, H. (2014). Orígenes de la psicología discursiva y su desarrollo hacia una psicología cultural posmoderna. Cuhso. Cultura-Hombre-Sociedad, 24(2), 43-57. Doi:http://dx.doi.org/10.7770/cuhso-V24N2-art854.

Campos, M. (2017). Aprender por el cuerpo: una propuesta de educación para la diversidad en la escuela. En K. Carreño, Memorias del Congreso Internacional de Educación para el Desarrollo en perspectiva Latinoamericana. I Congreso Convergencias y divergencias. Hacia educaciones y desarrollos otros. Corporación Universitaria Minuto de Dios-Uniminuto, sede principal, Bogotá.

Cárdenas, L., Parrado, Y. y Romero, Y. (2012). Educación superior inclusiva (tesis de especialización en Gerencia Educativa). Universidad de la Sábana, Bogotá.

Carreño, O. (2008). Enfermedad motora de origen cerebral. En A. Marín, J. Jaramillo, J. Gómez y L. Gómez, Manual de pediatría ambulatoria (pp. 147-150). Bogotá: Editorial Panamericana.

Chacón, P. (2016). Educación superior incluyente: un estudio de caso a partir del análisis de la gestión administrativa de la subdirección de bienestar universitario de la Universidad Pedagógica Nacional (tesis de especialización en Gerencia Social de la Educación). Universidad Pedagógica Nacional, Bogotá.

Cole, M. (1990). Psicología cultural una disciplina del pasado y del futuro. Madrid: Morata.

Courtine, J. (2006). Historia del cuerpo (vol. 3. Las mutaciones de la mirada. El siglo xx). Madrid: Taurus.

Díaz, R. (2012). Discapacidad y mirada colonial. Reflexiones desde perspectivas feministas y descoloniales. En M. Almeida y M. Angelino (comp.), Debates y perspectivas en torno a la discapacidad en América Latina. Universidad Nacional de Entre Ríos, Paraná, Argentina, (UNER).

Dueñas, A., y Lizarazo, A. (2009). El proceso de la inclusión de estudiantes sordos al proyecto curricular de Licenciatura en Biología de la Universidad Pedagógica Nacional. Una mirada en el marco del conocimiento 
profesional del profesor en biología (Trabajo de grado). Universidad Pedagógica Nacional, Bogotá.

Foucault, M. (1996). El orden del discurso. Buenos Aires: Tusquets.

Foucault, M. (2007). Historia de la sexualidad 1. La voluntad del ser. México: Siglo xxı.

Garay, A., Iñiguez, L. y Martínez, L. (2005). La perspectiva discursiva en psicología social. Subjetividad y Procesos Cognitivos, 7, 105-130. Recuperado de http://www.redalyc.org/articulo.oa?id=339630246006.

Garzón, K. y Molina, R. (2014). Incluser del apoyo, a la participación y reconocimiento de estudiantes con discapacidad en la Universidad del Rosario. Documento de investigación, Escuela de Medicina y Ciencias de la Salud. Bogotá: Editorial Universidad del Rosario.

Gonzales, M. y Macias, L. (2008). Manejo ortésico del pulgar en niños con enfermedad motriz de origen central. Umbral Científico, 12, 52-64. Recuperado de http://www.redalyc.org/articulo.oa?id=30401205.

González-Domínguez, C. y Martell-Gámez, L. (2013). El análisis del discurso desde la perspectiva foucauldiana: método y generación del conocimiento. Ra Ximhai, 9(1), 153-172. Recuperado de http://oai. redalyc.org/articulo.oa?id=46126366013.

Heredia, N. (2012). Corporalidades, subjetividades y discapacidad: hacia una des-educación de los sentidos y sentires. En M. Almeida y M. Angelino (comp.), Debates y perspectivas en torno a la discapacidad en América Latina. Universidad Nacional de Entre Ríos (UNER), Argentina.

Jiménez, V. y Comet, C. (2016). Los estudios de casos como enfoque metodológico. Academo. Revista de Investigación en Ciencias Sociales y Humanidades, 3(2). Recuperado de http://revistacientifica.uamericana.edu.py/index.php/academo/article/view/92.

Leguizamón, F. y Molano, M. (2014). Caracterización de los procesos de gestión en la inclusión de estudiantes con discapacidad del Programa de Educación Especial de la Universidad Pedagógica Nacional (tesis de especialización en Gerencia Social de la Educación). Universidad Pedagógica Nacional, Bogotá.

Melo, D. (2014). Discapacidad y educación superior: sistematización de una experiencia (tesis de maestría en Educación). Universidad Pedagógica Nacional, Bogotá.

Ministerio de Educación Nacional y Corporación Unificada de Educación Superior (CUN). (2014). Educación superior inclusiva una experiencia en la CUN: una mirada al proceso de modificación y fortalecimiento curricular con enfoque en educación inclusiva. Bogotá: Ministerio de Educación Nacional.

Ministerio de Educación Nacional y Universidad Nacional Abierta y a Distancia. (2014). Educación inclusiva en la educación superior 
en Colombia y en la Universidad Nacional Abierta y a Distancia - UNAD-. Estado del arte. Bogotá: Ministerio de Educación Nacional.

Observatorio de la Universidad Colombiana. (2016). Ser Pilo Paga, una peligrosa estrategia de debilitamiento de la universidad pública. Observatorio de la Universidad Colombiana. Recuperado de http://www. universidad.edu.co/index.php/noticias/14219-ser-pilo-paga-una-peligrosa-estrategia-de-debilitamiento-de-la-universidad-publica.

Planella, J. (2016). Cuerpo, cultura y vulnerabilidad en la sociedad contemporánea: estudio de caso de un trasplante hepático. Cultura de los Cuidados, 20(45), 12-24. Doi.org/10.14198/cuid.2016.45.02.

Salinas, M., Lissi, M., Medrano, D., Zuzulich, M. y Hojas, A. (2013). La inclusión en la educación superior: desde la voz de estudiantes chilenos con discapacidad. Revista Iberoamericana de Educación, 63, 77-98.

Tamayo, A. y Naranjo, D. (2013). Mesa interuniversitaria por la discapacidad tejiendo redes de inclusión: sistematización de la experiencia. Cali: Ministerio de Educación Nacional, Pontificia Universidad Javeriana, Movimiento de Educación Popular Fe y Alegría.

Truscelli, D., Le Matayer, M. y Leroy-Malherbe, V. (2006). Enfermedad motora cerebral. Kinesiterapia-Medicina Física, 27(3), 1-18.

Vignolo, P. (2008). Cuerpos anómalos. Bogotá: Universidad Nacional de Colombia, Facultad de Ciencias Humanas y Sociales. 